\title{
Treatment of Bilateral Proximal Humeral Fracture in Patients with Parkinson's Disease: A Case Report
}

\author{
Hiromitsu Takano, Takatoshi Okuda, Ikuho Yonezawa, Kazuo Kaneko \\ Department of Orthopedic Surgery, Juntendo University School of Medicine, \\ Tokyo, Japan \\ Email: hrtakano@juntendo.ac.jp
}

Received 9 June 2016; accepted 17 July 2016; published 20 July 2016

Copyright (C) 2016 by authors and Scientific Research Publishing Inc.

This work is licensed under the Creative Commons Attribution International License (CC BY). http://creativecommons.org/licenses/by/4.0/

\begin{abstract}
There are only a few reports about upper extremity fractures in patients with Parkinson's disease (PD). This is a case report of a PD patient with severe tremors who had proximal humeral fracture. We performed surgery for the left side and conservative treatment for the right side. The patient was a 73-year-old woman who had been diagnosed with PD 10 years prior to presentation. Open reduction internal fixation was conducted for the left proximal humeral fracture. 7 months after the left shoulder fracture, she fell resulting in a right proximal humeral fracture for which she underwent conservative treatment. Although bone union was obtained bilaterally, anterior subluxation occurred in the operated side 9 months postoperative. Screw remove was performed because perforation of the screw was observed in the humeral head and was causing pain. Currently, restriction in range of motion and subluxation may be seen on the side that received conservative treatment, although pain is absent and patient satisfaction is high. On the operated side, there is a marked restriction in range of motion, subluxation, and pain. Our experience revealed that conservative treatment was effective for proximal humeral fractures and that optimal bone union might be obtained even in patients with suboptimal PD control.
\end{abstract}

\section{Keywords}

Parkinson's Disease, Proximal Humeral Fracture, Conservative Treatment

\section{Introduction}

Patients with PD have a high risk of fracture even under low energy because of postural impairments. Although

How to cite this paper: Takano, H., Okuda, T., Yonezawa, I. and Kaneko, K. (2016) Treatment of Bilateral Proximal Humeral Fracture in Patients with Parkinson's Disease: A Case Report. Open Journal of Orthopedics, 6, 234-239. 
there are many case reports about femoral neck fractures in patients with Parkinson's disease (PD), there are few reports on upper extremity fracture. This is a case report of a PD patient with severe tremors who had proximal humeral fracture. We performed surgery for the left side and conservative treatment for the right side.

\section{Case Report}

\section{Case: A 73-year-old woman}

Chief complaint: Shoulder pain

Medical history: PD

Family history: None

The patient had received treatment for Stage III PD according to the Yahr classification (the presence of postural impairment and gait impairment) at the neurology department of our hospital. The patient fell, injured her left shoulder, and was diagnosed with a left proximal humeral fracture at a local hospital and referred to our department. She was diagnosed with a left proximal humeral fracture Type C2 according to the AO classification and Group V 4-part according to the Neer classification based on radiography and computed tomography (CT) images (Figure 1). The patient was hospitalized for control of PD due to severe tremors, and open reduction internal fixation (ORIF) was performed 1 week post-injury (Figure 2). Although bone union was obtained 2 months after the surgery, tremors remained and anterior subluxation occurred in the operated side 9 months post-surgery. CT confirmed humeral head perforation of the screw, which resulted in pain (Figure 3). We performed screw remove for the proximal screws, and the crack sound diminished with improved pain relief (Figure 4). Range of motion of the left shoulder was $40^{\circ}, 40^{\circ},-10^{\circ}$, and $80^{\circ}$ for flexion, abduction, external rotation, and internal rotation, respectively (Table 1 ).

7 months after the left shoulder fracture, the patient fell and injured the right shoulder. The patient was diagnosed with a right proximal humeral fracture Type C2 according to the AO classification and Group V 4-part according to the Neer classification based on radiography (Figure 5). The patient was treated conservatively because of muscle weakness due to suboptimal control of PD, restricted range of motion (shoulder flexion of $90^{\circ}$ ), and poor outcomes in the operated side. We instructed the patient to start stooping exercises 1 week after the injury. The side treated with conservative treatment achieved optimal bone union 2 months after the injury, and there has been no pain 2 years after the injury, although there is deformation and anterior subluxation (Figure 6). The range of motion of the right shoulder joint was $80^{\circ}, 70^{\circ}, 0^{\circ}$, and $80^{\circ}$ for flexion, abduction, external rotation, and internal rotation, respectively (Table 1 ). The range of motion was mildly limited, preserving

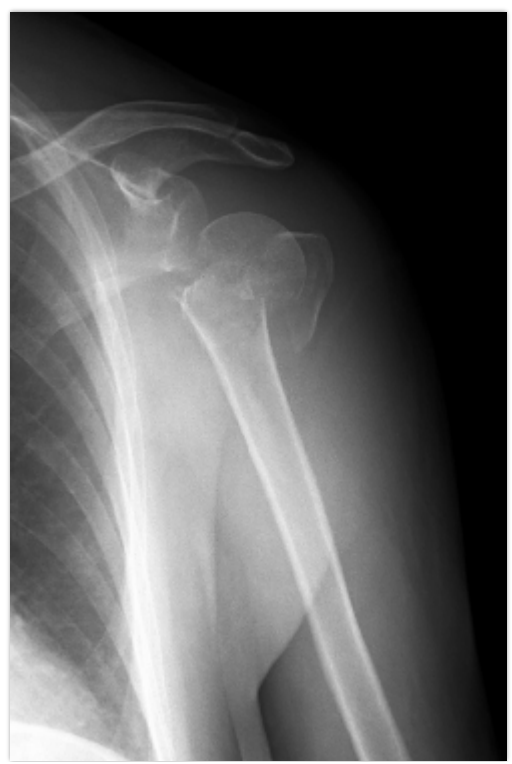

(a)

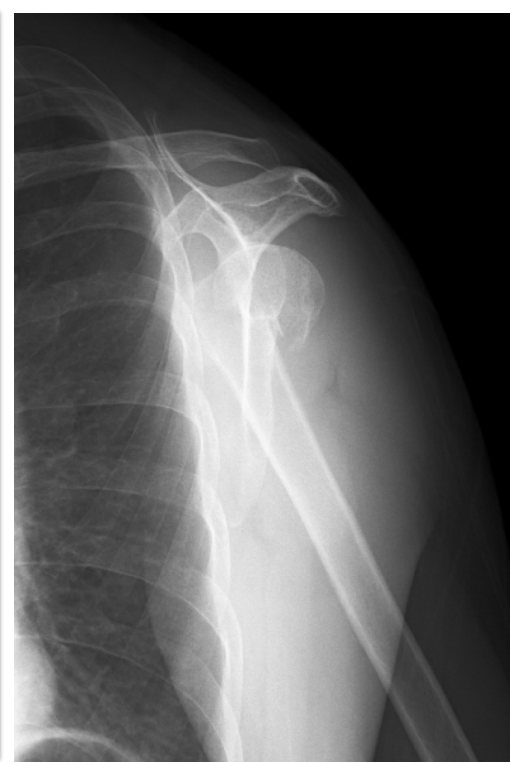

(b)

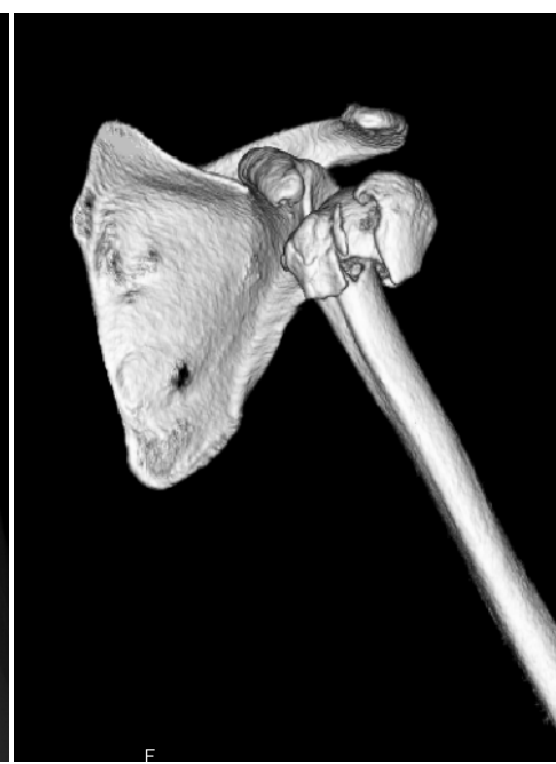

(c)

Figure 1. Left proximal humeral fracture at the time of injury: (a) Anterior-Posterior (AP) view of a plain radiograph; (b) Lateral scapula view of a plain radiograph; (c) 3D computed tomography scan. 


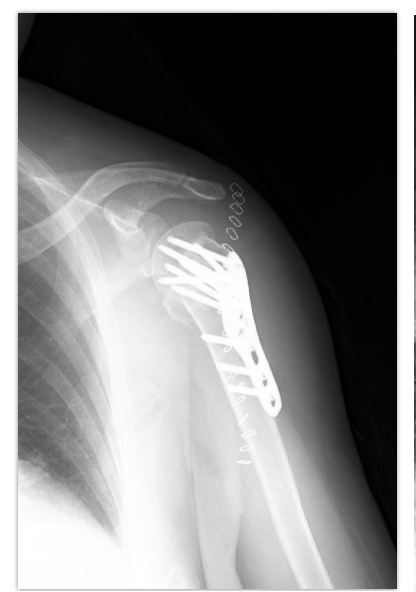

(a)

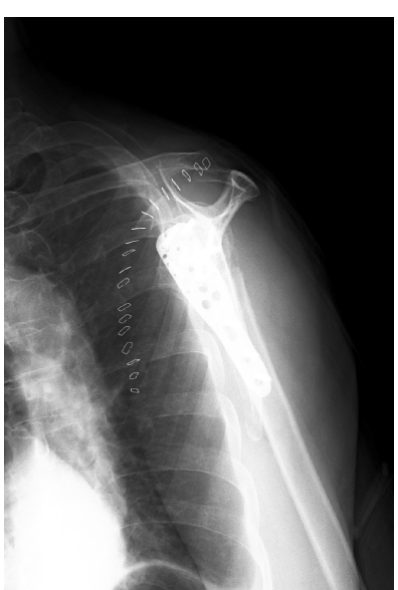

(b)

Figure 2. Post-ORIF surgery for left proximal humeral fracture: (a) AP view of a plain radiograph; (b) Lateral scapula view of a plain radiograph.

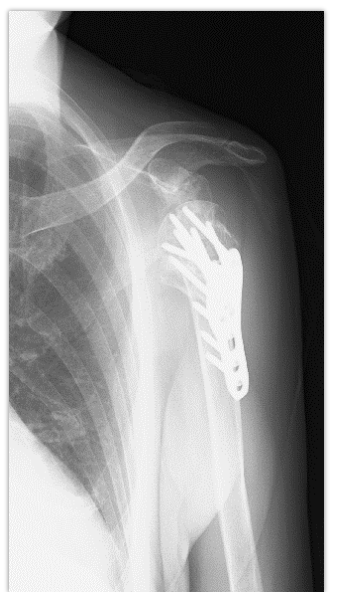

(a)

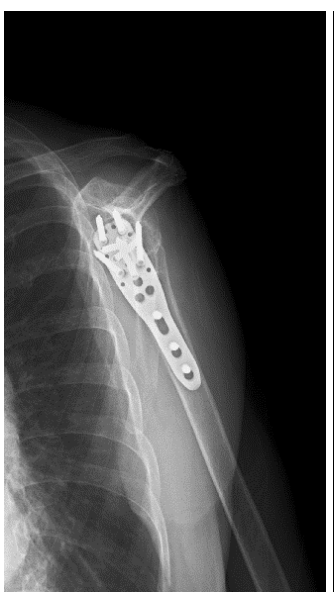

(b)

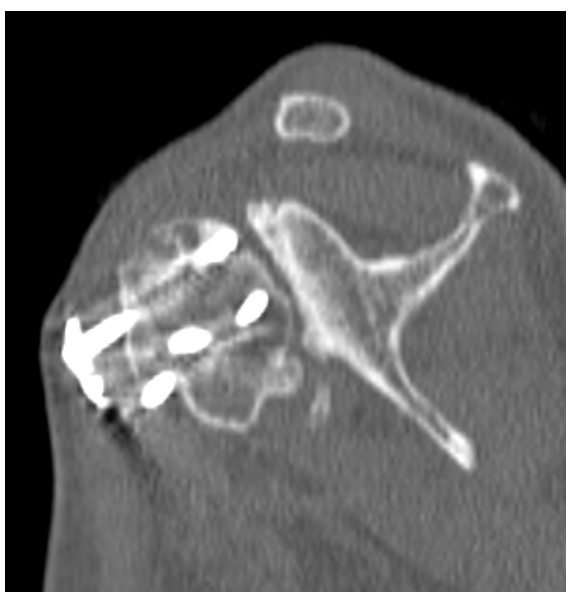

(c)

Figure 3. 9 months after the surgery, anterior subluxation and bone head perforation of the screw had occurred. (a) AP view of a plain radiograph; (b) Lateral scapula view of a plain radiograph; (c) Plain computed tomography scan.

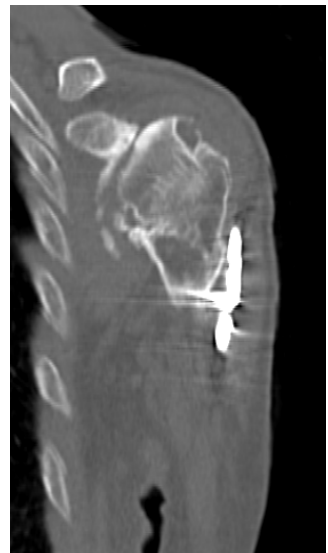

(a)

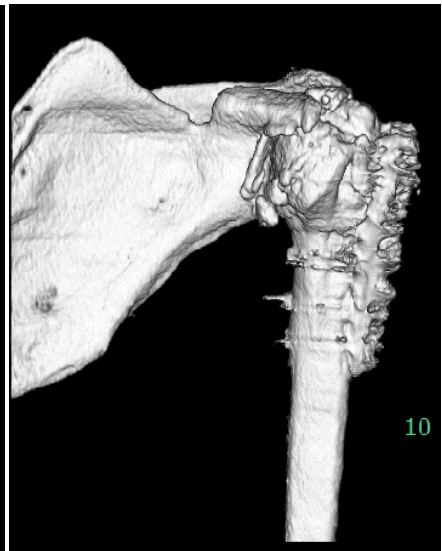

(b)

Figure 4. Screw remove was conducted only for proximal screws and bone union was observed. (a) Plain computed tomography scan; (b) 3D computed tomography scan. 


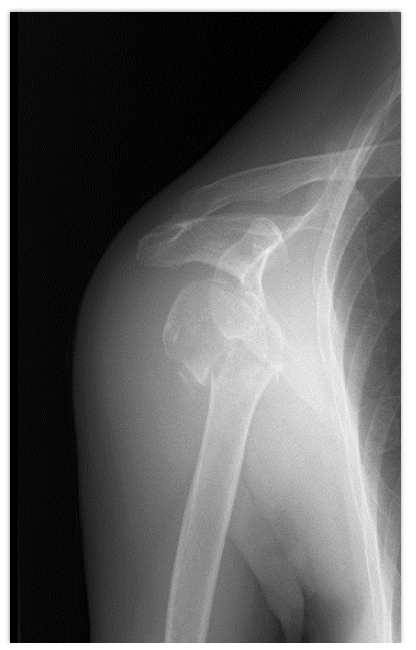

(a)

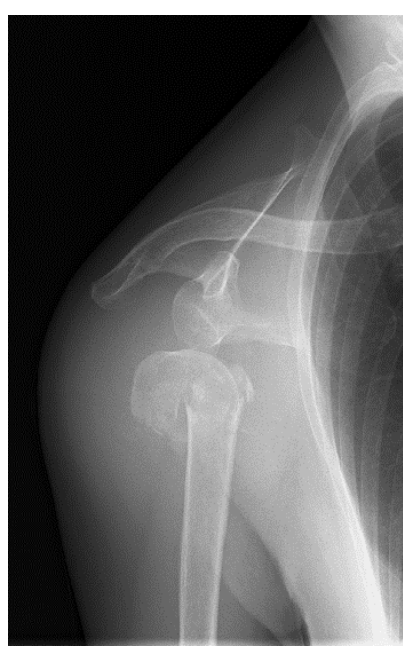

(b)

Figure 5. Right proximal humeral fracture: (a) AP view of a plain radiograph; (b) Lateral scapula view of a plain radiograph.

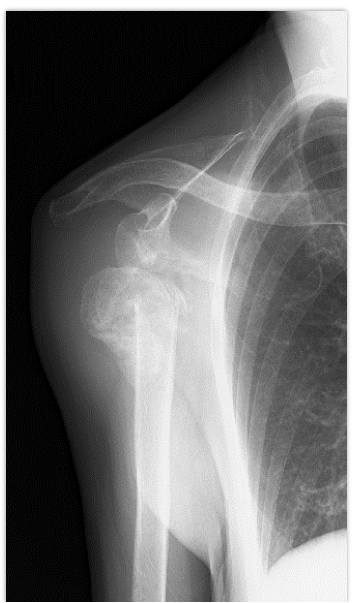

(a)

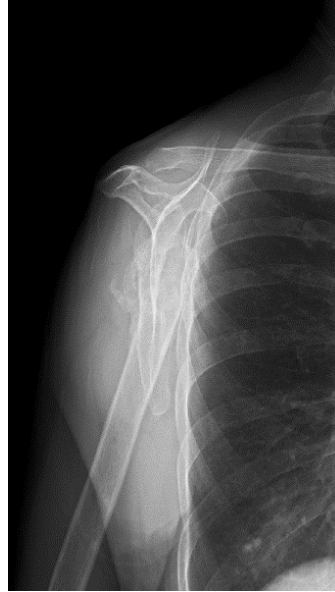

(b)

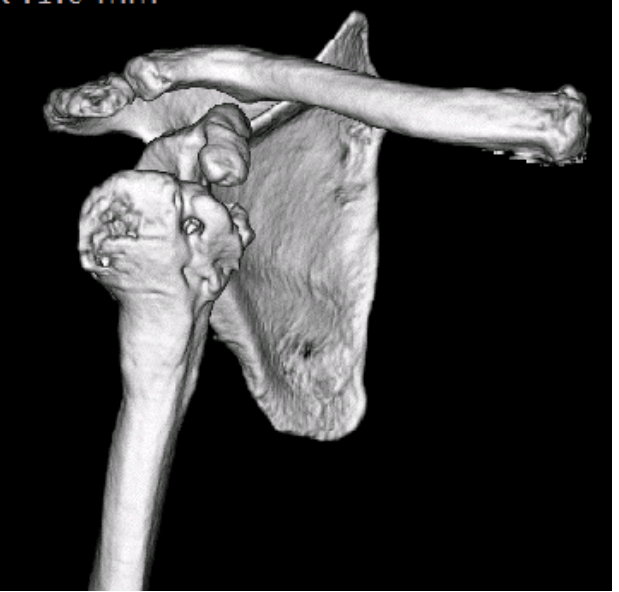

(c)

Figure 6. Right proximal humeral fracture 2 years after the injury. Deformed bone unionwas observed. (a) AP view of a plain radiograph; (b) Lateral scapula view of a plain radiograph; (c) 3D computed tomography scan.

Table 1. Acquired range of motion at the completion of treatment.

\begin{tabular}{ccccc}
\hline & Flexion & Abduction & External rotation & Internal rotation \\
\hline After surgery & $40^{\circ}$ & $40^{\circ}$ & $-10^{\circ}$ & $80^{\circ}$ \\
After conservative treatment & $80^{\circ}$ & $70^{\circ}$ & $0^{\circ}$ & $80^{\circ}$
\end{tabular}

functions required for activities of daily living (ADL). The patient was satisfied with the side that received conservative treatment.

\section{Discussion}

Patients with PD have a high risk of fracture even under low energy because of postural impairments. The prevalence of femoral neck fracture is high and there are several reports about it in the literature [1] [2], while very few reports about upper extremity fracture exist. Humeral head replacement and plate fixation are the surgical 
options in ORIF for proximal humeral fracture in patients with PD. However, to the best of our knowledge, there are only a few reports about humeral head replacement in patients with PD [3]-[5]. Kryzak et al. reported that they performed humeral head replacement in 7 patients with PD; $57 \%$ had subluxation and $43 \%$ had pain, resulting in poor outcomes [5]. Metz et al. reported that among 5 PD patients who had upper extremity fractures, all the patients who were treated conservatively lost the initial reduction positions and they suggested that ORIF with a firm fixation was effective [6]. In general, however, orthopedic surgeries for PD patients are considered difficult due to implant dislocation caused by tremor and progression of PD symptoms [7]. Furthermore, several recent studies suggest that bone strength in PD patients is decreased due to Vitamin D deficiency, secondary hyperparathyroidism, freezing and decreased activity, and medications [8]-[10].

The advantages of ORIF are stability, bone union, and better range of motion due to firm fixation, while its disadvantage is the surgical difficulty caused by weakened bone and difficult reduction. Furthermore, similar to the present case, many patients do not have ideal outcomes after ORIF and progression of OA occurs because these patients experience deformation, subluxation, restricted range of motion, and pain due to specific symptoms of PD such as decreased muscle tone and severe tremors. The right side, which received the conservative treatment, achieved optimal bone union 2 months after the injury, despite severe tremors. The restriction of the range of motion was mild and there was no pain but reduction was not complete. Moreover, in patients with poor PD control, the range of motion restrictions is severe and ADL independence is not appreciable. Thus, we believe that orthopedic surgery is not the sole option because bone union can be obtained with conservative treatments and functions required for ADL can be regained.

\section{Conclusion}

We reported a patient with PD who had proximal humeral fracture. The patient underwent surgical treatment for the left side and received conservative treatment for the right side. Conservative treatment was effective for the proximal humeral fracture and optimal bone union might be obtained even in patients with suboptimal PD control.

\section{Acknowledgements}

Written informed consent was obtained from the patient for publication of this paper and for the use of any accompanying images.

\section{Conflict of Interest}

The authors report no conflict of interest concerning the findings specified in this paper.

\section{References}

[1] Yuasa, T., Maezawa, K., Nozawa, M. and Kaneko, K. (2013) Surgical Outcome for Hip Fractures in Patients with and without Parkinson's Disease. Journal of Orthopaedic Surgery, 21, 151-153.

[2] Clubb, V.J., Clubb, S.E. and Buckley, S. (2006) Parkinson's Disease Patients Who Fracture Their Neck of femur: A Review of Outcome Data. Injury, 37, 929-934. http://dx.doi.org/10.1016/j.injury.2005.11.013

[3] Koch, L.D., Cofield, R.H. and Ahlskog, J.E. (1997) Total Shoulder Arthroplasty in Patients with Parkinson’s Disease. Journal of Shoulder and Elbow Surgery, 6, 24-28. http://dx.doi.org/10.1016/S1058-2746(97)90067-7

[4] Kryzak, T.J., Sperling, J.W., Schleck, C.D. and Cofield, R.H. (2009) Total Shoulder Arthroplasty in Patients with Parkinson's Disease. Journal of Shoulder and Elbow Surgery, 18, 96-99. http://dx.doi.org/10.1016/j.jse.2008.07.010

[5] Kryzak, T.J., Sperling, J.W., Schleck, C.D. and Cofield, R.H. (2010) Hemiarthroplasty for Proximal Humerus Fractures in Patients with Parkinson's Disease. Clinical Orthopaedics and Related Research, 468, 1817-1821. http://dx.doi.org/10.1007/s11999-010-1353-1

[6] Metz, C.M., Tsai, E. and Louis, D.S. (2001) Upper Extremity Fractures and Parkinson’s Disease. Orthopedics, 24, 66-68.

[7] Zuckerman, L.M. (2009) Parkinson’s Disease and the Orthopaedic Patient. Journal of the American Academy of Orthopaedic Surgeons, 17, 48-55. http://dx.doi.org/10.5435/00124635-200901000-00007

[8] Van, Den, Bos, F., Speelman, A.D., Samson, M., Munneke, M., Bloem, B.R. and Verhaar, H.J. (2013) Parkinson’s Disease and Osteoporosis. Age and Ageing, 42, 156-162. http://dx.doi.org/10.1093/ageing/afs161 
[9] Van, Den, Bos, F., Speelman, A.D., Van, Nimwegen, M., Van, Der, Schouw, Y.T., Backx F.J., Bloem, B.R, Munneke, M. and Verhaar H.J. (2013) Bone Mineral Density and Vitamin D Status in Parkinson's Disease Patients. Journal of Neurology, 260, 754-760. http://dx.doi.org/10.1007/s00415-012-6697-X

[10] Zhao, Y., Shen, L. and Ji, H.F. (2013) Osteoporosis Risk and Bone Mineral Density Levels in Patients with Parkinson’s Disease: A Meta-Analysis. Bone, 52, 498-505. http://dx.doi.org/10.1016/j.bone.2012.09.013

\section{Submit or recommend next manuscript to SCIRP and we will provide best service for you:}

Accepting pre-submission inquiries through Email, Facebook, LinkedIn, Twitter, etc.

A wide selection of journals (inclusive of 9 subjects, more than 200 journals)

Providing 24-hour high-quality service

User-friendly online submission system

Fair and swift peer-review system

Efficient typesetting and proofreading procedure

Display of the result of downloads and visits, as well as the number of cited articles

Maximum dissemination of your research work

Submit your manuscript at: http://papersubmission.scirp.org/ 